\title{
Características operativas de los marcadores inflamatorios para el diagnóstico de enfermedades infecciosas, autoinmunes y oncológicas en el ámbito de atención primaria
}

\author{
Operational characteristics of inflammatory markers for the diagnosis of infectious, autoimmune and oncological \\ diseases in the primary care setting
}

\section{Comentado de:}

Watson J, et al. Br J Gen Pract. 2019; 69 (684): e470-e478. PMID: $31208976^{1}$

\section{Objetivo}

Identificar el valor de los marcadores inflamatorios en el contexto de la atención primaria para descartar enfermedades relevantes.

\section{Diseño y lugar}

Estudio de cohorte prospectiva, realizado con datos de los registros electrónicos de salud del ámbito de la atención primaria del Reino Unido.

\section{Pacientes}

Se incluyeron 136.961 pacientes mayores de 18 años de edad testados durante 2014 con marcadores inflamatorios (grupo expuesto) y 37.539 , sin testear (grupo control) durante el mismo año, que al momento de ingresar a la cohorte no tuvieran el diagnóstico de infecciones o cánceres activos, ni de enfermedades autoinmunes.

\section{Descripción de las pruebas testeadas (pruebas índice)} y de las pruebas de referencia (gold standard)

Las pruebas testeadas fueron la proteína $C$ reactiva (PCR), el volumen de sedimentación globular (VSG) y la viscosidad plasmática (VP).

La prueba de referencia fue la incidencia a diferentes horizontes temporales de tres grandes categorías de enfermedades relevantes: 1) infecciones (un mes), 2) afecciones autoinmunes (un año), 3) cánceres (un año).

\section{Resultados principales}

Del total de la cohorte testeada, el $27,8 \%$ de los pacientes presentó al menos un marcador inflamatorio elevado: PCR $71 \%$,
VSG $58 \%$, y VP 10,1\% (la suma de los porcentajes supera el $100 \%$ porque a algunos pacientes se les pidió más de un marcador). La incidencia de enfermedades relevantes en los diferentes grupos se describe en la Tabla 1 y la Tabla 2. Las características operativas de cada prueba testeada se describen en la Tabla 3.

Tabla 1. Incidencia global de enfermedades relevantes de acuerdo a los resultados de marcadores inflamatorios en una cohorte de pacientes testeados y en un grupo control de personas no testeadas, en el ámbito de la atención primaria.

\begin{tabular}{|l|l|c|}
\hline Grupos evaluados & \multicolumn{1}{|c|}{$\begin{array}{c}\text { Resultados de los } \\
\text { marcadores }\end{array}$} & $\begin{array}{c}\text { Incidencia de } \\
\text { enfermedades } \\
\text { relevantes }\end{array}$ \\
\hline $\begin{array}{l}\text { Pacientes testeados } \\
(\mathrm{n}=136.961)\end{array}$ & $\begin{array}{l}\text { Alterado, } \\
\mathrm{n}=38.010(28 \%)\end{array}$ & $15 \%$ \\
\cline { 2 - 3 } & $\begin{array}{l}\text { Normal, } \\
\mathrm{n}=98.951(72 \%)\end{array}$ & $6 \%$ \\
\hline \multicolumn{2}{|l|}{ Grupo control $(\mathrm{n}=37.539)$} & $3,4 \%$ \\
\hline
\end{tabular}

Tabla 2. Incidencia específica de enfermedades relevantes de acuerdo a los resultados de marcadores inflamatorios en una cohorte de pacientes testeados, en el ámbito de la atención primaria.

\begin{tabular}{|l|c|c|}
\hline Pruebas de referencia & $\begin{array}{c}\text { Resultados } \\
\text { alterados }\end{array}$ & $\begin{array}{c}\text { Resultados } \\
\text { normales }\end{array}$ \\
\hline Infecciones & $6,3 \%$ & $2,9 \%$ \\
\hline Enfermedades autoinmunes & $5,6 \%$ & $1,7 \%$ \\
\hline Cáncer & $3,7 \%$ & $1,5 \%$ \\
\hline
\end{tabular}

Tabla 3. Características operativas de los marcadores inflamatorios estudiados considerando como prueba de referencia al desarrollo de al menos una enfermedad relevante (infecciosas al mes, cáncer y autoinmunes al año). Notas: IC: Intervalo de Confianza; VPN: Valor Predictivo Negativo; VPP: Valor Predictivo Positivo.

\begin{tabular}{|l|c|c|c|c|}
\hline Prueba evaluada & Sensibilidad (IC 95\%) & Especificidad (IC 95\%) & VPP (IC 95\%) & VPN (IC 95\%) \\
\hline Proteína C Reactiva & $45,6 \%(44,5$ a 46,6) & $78,8 \%(78,6$ a 79,1$)$ & $17,4 \%(16,9$ a 17,9$)$ & $93,7 \%(93,5$ a 93,9$)$ \\
\hline Velocidad de Sedimentación Globular & $42,0 \%(40,8$ a 43,2) & $78,6 \%(78,3$ a 78,9$)$ & $15,1 \%(14,6$ a 15,7$)$ & $93,7 \%(93,5$ a 93,9$)$ \\
\hline Viscosidad Plasmática & $46,5 \%(43,6$ a 49,4) & $74.4 \%(73,7$ a 75,2$)$ & $13,9 \%(12,9$ a 15,1$)$ & $93,9 \%(93,4$ a 94,3$)$ \\
\hline
\end{tabular}

\section{Conclusiones}

Los marcadores inflamatorios tienen una sensibilidad menor al $50 \%$ y no deberían usarse como prueba de descarte de enfermedades relevantes en el ámbito de la atención primaria. Por su especificidad menor al $80 \%$, los resultados falsos positivos son comunes y conducen a un aumento en las tasas de consultas al médico de atención primaria, en la solicitud de nuevos exámenes y en las derivaciones a otros especialistas. 
Fuente de financiamiento/Conflicto de interés de los autores: No referida.

\section{Comentario}

La solicitud de marcadores inflamatorios es común en el contexto de la atención primaria como una prueba para descartar enfermedad subyacente grave ${ }^{2}$. Sin embargo, los resultados inesperados pueden ser difíciles de interpretar, mientras que los resultados falsamente positivos -aproximadamente $24 \%$ en esta investigación- pueden conducir a una mayor ansiedad tanto en el paciente como en el médico tratante y generar una cascada de pruebas y consultas adicionales ${ }^{3}$. A su vez, los resultados falsos negativos $-50 \%$ en este trabajo- pueden dar lugar a falso reaseguro.

Por otro lado, gran parte de la evidencia sobre los marcadores inflamatorios proviene de estudios realizados en el ámbito de la atención secundaria y se han centrado en la descripción clínica de pacientes con una única enfermedad ${ }^{4}$. Por esta razón, dicha evidencia no es útil para interpretar lo que sucede ante pacientes con síntomas no específicos, en quienes existe la sospecha de un espectro más amplio de enfermedades.

El objetivo de este estudio fue identificar la utilidad de los marcadores inflamatorios más usados en el ámbito de la atención primaria como una prueba de descarte, proporcionar evidencia para que los médicos generalistas interpreten los resultados de los marcadores inflamatorios y, secundariamente, procuren cuantificar las cascadas de pruebas diagnósticas generadas a partir de los resultados de estas pruebas.

La principal limitación de este trabajo es que ha analizado conjuntamente, como si fuera un gran grupo homogéneo, a diferentes subpoblaciones de pacientes que merecerían algún tipo de análisis de subgrupo. Debido a que esta investigación utilizó datos secundarios recolectados en el contexto de la atención primaria, es probable que la calidad del registro de los motivos por los cuales los médicos actuantes solicitaron los marcadores inflamatorios, no haya sido suficiente. Por ejemplo, seguramente fue difícil para el equipo investigador discriminar los pacientes en quienes los marcadores fueron pedidos ante una sospecha clara de alguna entidad clínica ( $p$. ej. polimialgia reumática), de quienes estos análisis fueron pedidos para reasegurarlos ante síntomas inespecíficos o bien, en el contexto de un análisis de rutina.

\section{Conclusiones de la comentadora}

Las características operativas de los marcadores inflamatorios no serían buenas en el ámbito de la atención primaria para descartar ni para confirmar enfermedad relevante. Sin embargo, los autores de esta investigación no han tenido la posibilidad de discriminar subgrupos de pacientes en los que sería esperable que las características operativas de estas pruebas se comportasen de un modo diferente. Por esta razón, consideramos que es difícil extrapolar sus conclusiones a subgrupos específicos de pacientes con diferente probabilidad pretest de enfermedades específicas.

Malena Chiaborelli [ Servicio de Medicina Familiar y Comunitaria, Hospital Italiano de Buenos Aires. malena.chiaborelli@hospitalitaliano.org.ar ]

Chiaborelli M. Características operativas de los marcadores inflamatorios para el diagnóstico de enfermedades infecciosas, autoinmunes y oncológicas en el ámbito de atención primaria. Evid Actual Pract Ambul. 2020;23(4):e002066. Comentado de: Watson J, et al. Added value and cascade effects of inflammatory marker tests in UK primary care: a cohort study from the Clinical Practice Research Datalink. Br J Gen Pract. 2019 ; 69 (684): e470-e478. PMID: 31208976

\section{Referencias}

1. Watson J, Salisbury C, Whiting P. Added value and cascade effects of inflammatory marker tests in UK primary care: a cohort study from the Clinical Practice Research Datalink. Br J Gen Pract. 2019;69(684):e470-e478. Available from: 10.3399/bjgp19X704321.

2. Watson J, deSalis I, Hamilton W, et al. 'I'm fishing really' — inflammatory marker testing in primary care: a qualitative study. Br J Gen Pract. 2016;(644):e200-6. Available from: 10.3399/bjgp16X683857.

3. Watson J, deSalis I, Banks J, et al. What do tests do for doctors? A qualitative study of blood testing in UK primary care. Fam Pract. 2017;34(6):734739. Available from: 10.1093/fampra/cmx051.

4. Watson J, Round A, Hamilton W. Raised inflammatory markers. BMJ. 2012;344:e454. Available from: 10.1136/bmj.e454. 